\title{
3-D model of the blast freezer
}

\section{National University of Food Technologies, Kyiv, Ukraine}

Yaroslav Zasiadko

\begin{abstract}
The developed 3-D model of the blast freezer showed its adequacy of simulated processes to those observed in practice. It has shown its versatility and high flexibility as per the range of the variable data which can be changed in the process of simulation, and thus whose influence can be studied. The model allow to determine the optimum positioning of pallets including the distance between them in files and rows providing the highest efficiency of the process, as per the cycle duration and compact loading of freezer per cycle. The model can be used at a stage of freezer and air distribution designing calculations.
\end{abstract}

Corresponding author: Yaroslav Zasiadko

E-mail: iaroslav@nuft.edu.ua

DOI: $10.24263 /$ RES-2018-7

\section{Introduction}

Shock freezing technology is the most proper way to extending the shelf life of meat and poultry products along with the preserving the product quality, including its organoleptic properties. This technology involves thermal processing the product with a low temperature air $\left(-35 \ldots-40^{\circ} \mathrm{C}\right)$, flowing over the product at a high velocity, which significantly increases the heat fow removed from product, thus reducing freezing time. In shock freezing process water molecules form minute crystals whereas at freezing at moderate speed, macrocrystals are formed that destroy the cellular structure of the product, which badly affects its organoleptic qualities. Particularly negative are the consequences of the macrocrystals formation during the freezing of meat products, since large crystals destroy the structure of fibrous tissues and cell walls. When defrosting, such meat has a laced structure, intensively secretes juice, loosing food quality[1-4,6,10].

Typically, the products in the cages on pallets are placed in rows along the tunnel, which is partitioned a false ceiling. The upper section generates a directed flow of air cooled down to $-35 \ldots-450 \mathrm{C}$ from the air cooler. The stream of cooled air passes above the distribution ceiling, turning down and then backward, cooling the products and warming up to the entrance to the air cooler thus producing the continuous circulation of air. In [1,2] a number of shock freezer layouts and types is presented. In addition to the above described, there are also designs of shock freezing chambers with 
ceiling-mounted air coolers which in contrast to the above does not need a separate compartment for air cooling unit and fan section.

The experience of using shock-frost cameras indicates the following [4, 6, 9-11].

1. Critical for the design and operation of blast freezers is proper air distribution providing uniform and effective air flow around products, which in turn determines short time freezing, lowering energy spent;

2. Optimal placement of cages with cooled down products in the tunnel (chamber) preventing obstructions to high-speed cold air flow to ensure the minimum freezing cycle duration is extremely important;

3. The thermal load of shock freezing in time is extremely uneven and varies from the maximum, and then gradually decreases to a minimum at the end of the freezing cycle, since the heat transfer from the goods decreases gradually as they freeze lowering temperature difference;

The optimum number of blast freezer tunnels (chambers) should be determined with taking into account the attainable uniformity of the total daily cooling load. Thus, the time table of loading- freezing - unloading operations is to be arranged in shifts, whereas each next cycle starts after the cooling load of the previous one has decreased not less than be $40 \%$ of its maximum value.

From the stated above, it can be deduced that the critical factor in the design of shock freezing chambers is the adequate calculation of the cooled air velocity fields when it flows around the products in cages [7-9]. In addition, in determining of the distribution of airflow in the freezing chambers, there appears a question of the optimum placement of pallets with cages in the chamber (tunnel), since on the one hand there is a need to fill the chamber as compact as possible and, on the other hand, too dense a loading seriously complicates the circulation of air between the cages and, accordingly, worsens heat transfer, which, in turn, prolongs the freezing cycle [5,6]

\section{Design and calculation practices analysis}

For the transient process of product cooling down without phase change within a time increment $\mathrm{d} \tau$ the heat balance will read:

$$
d Q=\rho_{m} V C_{p m} d T,
$$

Where $\rho_{m}$-mean product density,$V$-product volume, $C_{p m}$ - mean product specific heat, $T-T(\tau)$-current product temperature.

The amount of heat removed from the cooled down product to the flowing around air will be:

$$
d Q=\alpha F_{m}\left[T_{m}(\tau)-T_{\infty}\right] d(\tau),
$$

where $T_{m}(\tau)$-current temperature of product, $T_{\infty}$ - temperature of the flowing around air. $\alpha$ - heat transfer coefficient. 
Combining (1) and (2) one obtains ordinary differential equation which upon solving yields:

$$
\frac{T_{m}(\tau)-T_{\infty}}{T_{m 0}-T_{\infty}}=\exp \left(-\frac{\alpha F_{m}}{\rho_{m} V * C_{p m}} \tau\right),
$$

Or, solved for $\tau$ :

$$
\tau=\frac{\rho_{m} V * C_{p m}}{\alpha F_{m}} \operatorname{Ln} \frac{T_{m}(\tau)-T_{\infty}}{T_{m 0}-T_{\infty}} .
$$

It should be pointed out that the above equations are valid only under the suggestion of the uniform temperature distribution at any time within a cooled down product. In practice this suggestion never stays true, since at the given conditions the internal heat conduction in the cooled body will be dominant in determining the duration of cooling. The conjugated problem of the external heat transfer and internal heat conduction cannot be solved analytically even for a single cooled body. For a number of cages, being cooled down in a freezer, individual boundary conditions will be different (insofar the air flow around each cage may differ). Being coupled with the uncertainty in the determination of air flows around individual cage in freezer, the problem appears extremely complex. To date, unfortunately, there are no methods and methodology for calculating jets of air from fans flowing through the cage cluttered chambers. Moreover, there are no methods for calculating transient heat transfer from cooled bodies. In most cases, the design of the air distribution in the freezing chambers is solved on the basis of certain design experience and through the application of empirical equations, which, as a rule, have only limited applicability. In these conditions, the most promising is the application of 3-dimensional simulation of blast freezers, including modeling of aerodynamics and heat transfer to airflows in simulated, including the internal heat conduction within a cage itself.

\section{3-D model development}

The ANSYS CFX applications provide exceptional capabilities in this sense[].ANSYS Fluent software allows to create a 3-D shock freezer (tunnel) model in 1:1 scale at a given precision of detalization, which is limited only by the available capacity of computers and duration of calculations. This, in turn, allows to adequately displaying all the particulars of the blast freezer, including local aerodynamic parameters, turbulence, temperature distribution etc. Developing a set calculation grids of possible positioning of pallets inside the freezer and respective modeling of the process allows to pick up an optimum placement of cages aimed at the minimizing of freezing duration. The ANSYS CFX built-in grid generator programs allow generating grids of any complexity and boundary fineness (Workbench and ICEFM routines). The generated grid is transmitted to the ANSYS CFX preprocessor unit, which, in fact, runs the individual model. boundary conditions, including the initial temperature of the product, the temperature of the cooled air, boundary conditions on the walls, the ceiling 
and the floor, which allows to take into account the individual features of a particular project. It is also possible to enter parameters that allow to perform a variational calculations, aimed at the determining of optimal designs of air coolers, air deflectors, distributors etc $[5,7,9]$.

The simulation was carried out at the Department of Thermal Power Engineering and Refrigeration Technology of NNIITI named after Academician Guliy I.S. NUFT using the licensed ANSYS 15 Lic No 1023420 Acad software. The developed calculation grid of the modeled freezer is shown in Fig.1.

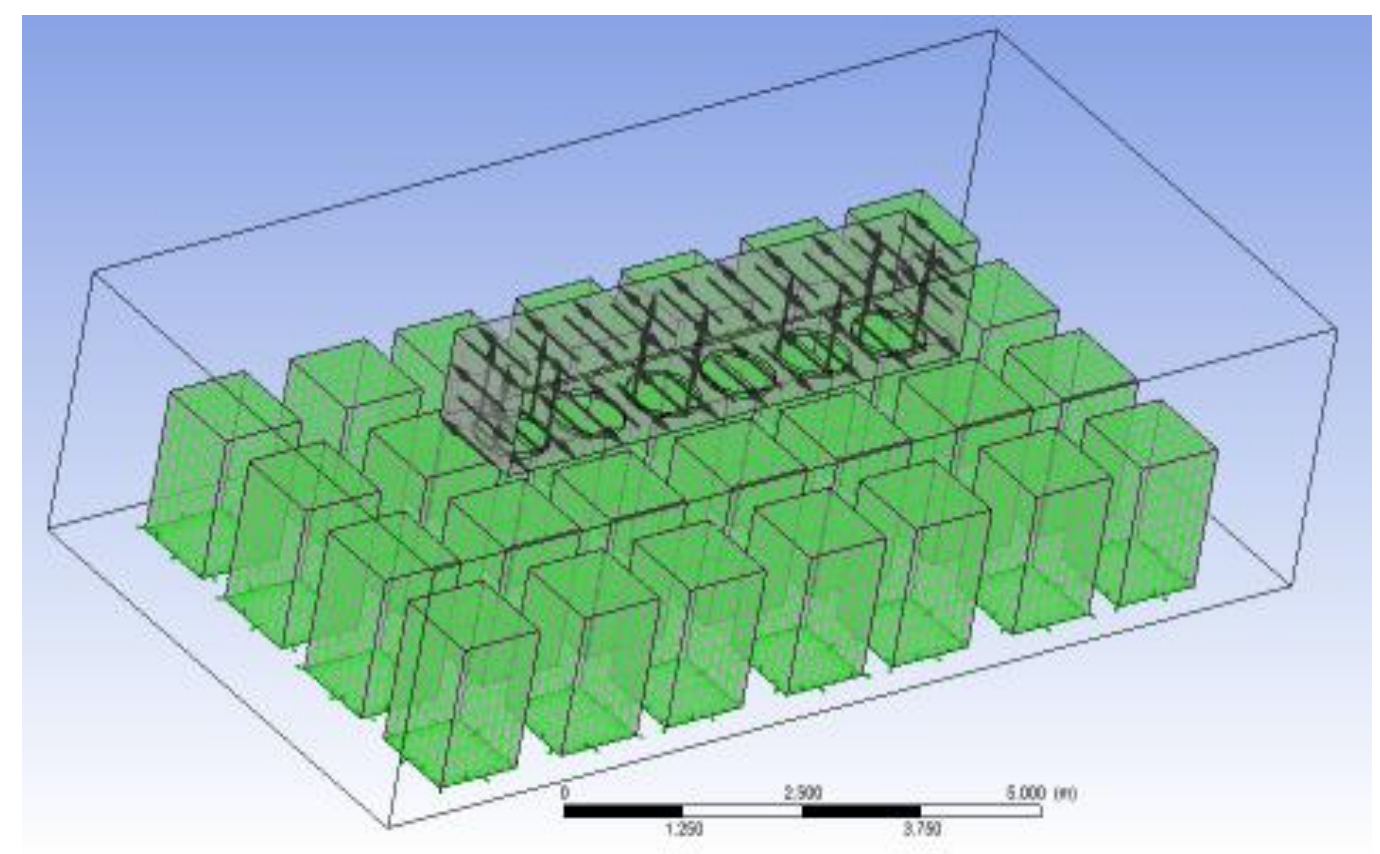

Fig.1. Calculation grid of the freezer with product cages on pallets and over hanging air cooler

Accepted size of the cage $-1 \times 1,2 \times 1,6$, which corresponds to the pallet size adopted in the meat industry. In this arrangement of pallets in the tunnel, the production capacity will be 17-20 t per cycle. The ANSYS CFX actually creates an environment in which it is possible to form a geometric entity that comprises two sub-domains. One is a cooling cabinet which forms a fluid sub-domain, in which the flow of cooled air takes place. The other- is a solid domain which includes a set of caged boxes on pallets arranged in a certain way and enveloped by the fluid sub-domain. The two sub-domains are thermally connected at the boundaries of every cage by postulating the heat flux conservation on the sub-domains" interfaces. This allows us to adequately capture all of the local aerodynamic parameters, including the turbulence scaling and the flow parameters in the wall boundary layers without the need for preliminary determination of the local heat transfer. As it is seen from Fig.1., the air is cooled down in the 
overhanging cooler with the fan intakes at the bottom of the cooler and the side wall grill distributors.

\section{Results and discussion}

The simulation of the transient regime of product cooling down has been performed with the variation of the cooling duration at $1 \mathrm{hr}$. step. The obtained results have sown their close adequacy to the data observed in practice. The analysis of the flow pattern through the snuggly packed freezer allowed discovering and locating the zones of poor air circulation and as a result of this poor heat transfer from the cages. Configuration of streamlines exiting the side grills of air coolers showed the necessity to address the issue of the special air distributor -deflector which will even the air flow and direct it uniformly towards the periphery of the side rows of pallets. This is in conformity with the results presented in[9].The temperature distribution along the line passing through the center of the row of cages adjacent to the axial line at different heights is presented in Fig 2 and 3.

As it is clearly seen from the data in Fig.2 and 3. The most efficient cooling takes place in the central part of rows (cages No 3,4,5). Which is quite clear due to the fact that the fan intakes create a powerful stream of air in this zone. In the contrast, the periphery cages remote from the fan intakes are located in the zones of poor circulation which is caused by the improper design of air distribution. Poor cooling in the lower parts of cages is also the result of weak streams of air penetrating a whole depth of the freezer, since there is no air deflector directing flow downwards, instead the air stream tend to move along the least resistance way - to turn backward and move to the fan intakes along the shortest unobstructed way. 
Resource and Energy Saving Technologies of Production and Packing of Food Products as the Main Fundamentals of Their Competitiveness: Proceedings of the 7th International Specialized Scientific and Practical Conference, September 13, 2018. Kyiv, Ukraine

Temperature distribution in product cages

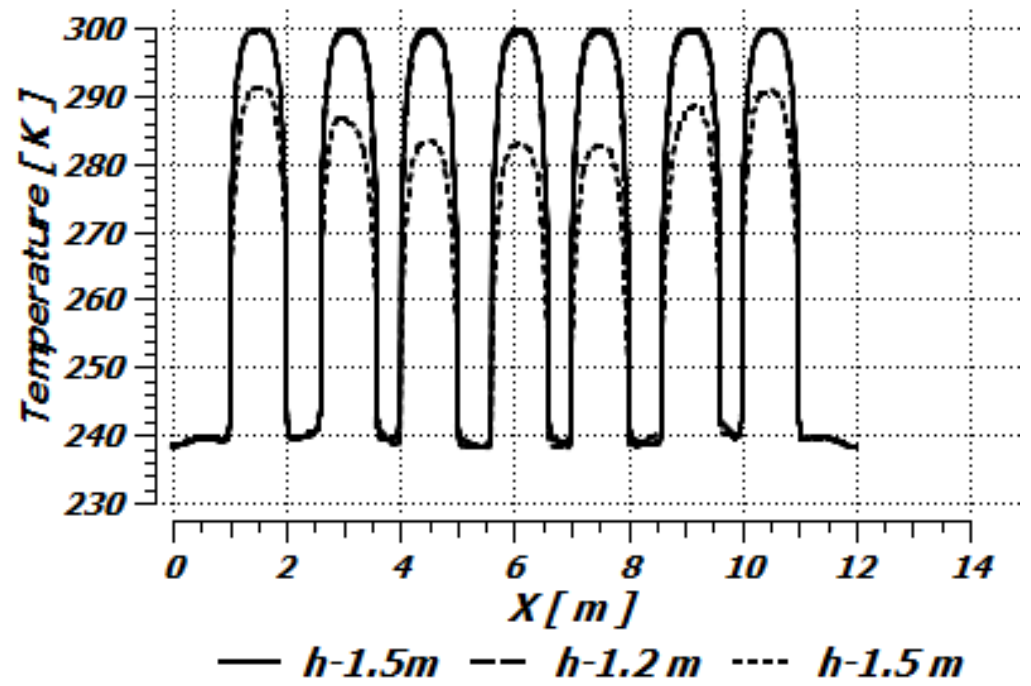

Temperature distribution in product cages

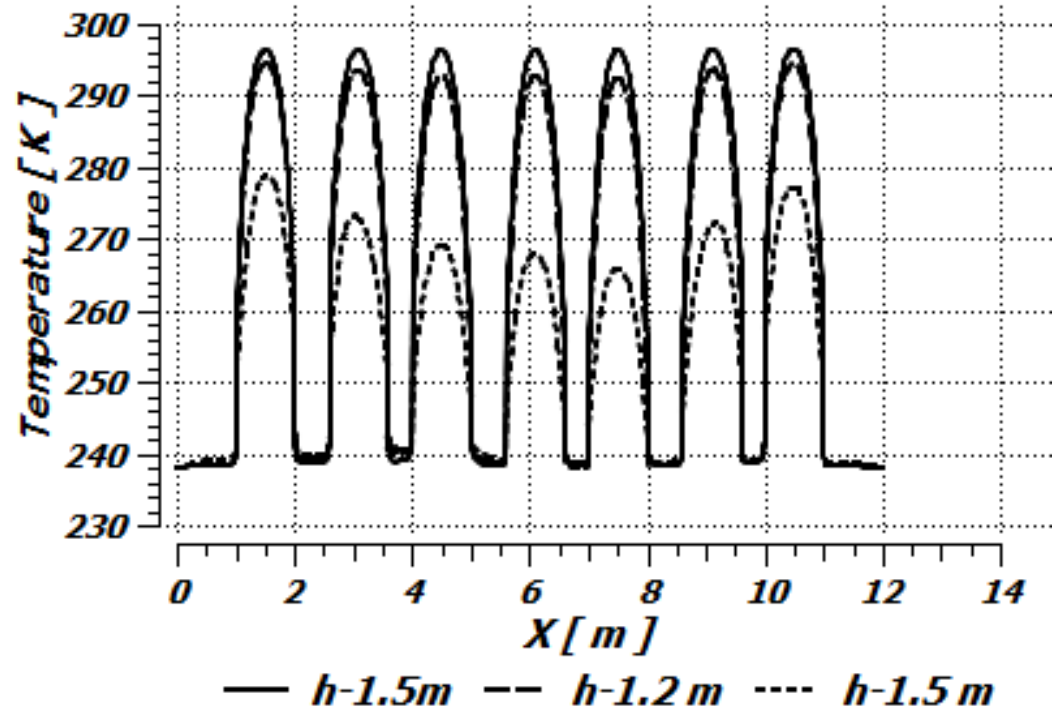

Fig. 3. Temperature distribution in freezer and cages. 12 hrs. cooling.

\section{Conclusions}

The developed 3-D model of the blast freezer showed its adequacy of simulated processes to those observed in practice. It has shown its versatility and high flexibility as per the range of the variable data which can be changed in the process of simulation, and thus whose influence can be studied. The model allow to determine the optimum positioning of pallets including the distance between them in files and rows providing the highest efficiency of the process, as per the cycle duration and compact loading of freezer per cycle. The model can be used at a stage of freezer and air distribution designing calculations. 


\section{References}

1. W.A. Johnston, F.J. Nicholson, A. Roger and G.D. StroudFreezing and refrigerated storage in fisheries. Freezers - FAO, Food and agriculture organization of the United Nations, Rome, 1994, http://www.fao.org/docrep/003/v3630e/v3630e05.htm

2. Gustavo V. Barbosa-Cánovas,Bilge Altunakar,Danilo J. Mejía-LorioFreezing of fruits and Vegetables. Food And Agriculture Organization Of The United Nations, Rome 2005, http://www.fao.org/docrep/008/y5979e/y5979e03.htm

3. Jihan F. Cepeda Jimenez, Modeling Heat Transfer During Cooling of Readyto-eat Meat and Poultry Products Using Threedimensional Finite Element Analysis and Webbased Simulation, Dissertations, Theses, and Student Research. 15., MSc. Degree, 2010, 145 p.

http://digitalcommons.unl.edu/cgi/viewcontent.cgi?article=1014\&context=bios ysengdiss

4. Jihan F Cepeda. Development and validation of heat and mass transfer models for meat carcass chilling, Thesises, Dissertation Ph.D. 2016, 155 p. https://search.proquest.com/docview/1810956264

5. Farzad Sepahvandi*, Hamid M. Heravi, Seyed R. Saleh Numerical simulation of fish meat freezing with considering temperaturedependent thermal properties, INTERNATIONAL JOURNAL OF HEAT AND TECHNOLOGY, ISSN: 0392-8764 Vol. 35, No. 1, March 2017, pp. 75-81, http://iieta.org/sites/default/files/Journals/IJHT/35.1_10.pdf

6. Husam Mahdi Hadi, Qasim S. Mahdi, Nessrian Ali Hussien. Experimental and numerical investigation of temperature distribution for meat during freezing process, International Journal of Mechanical Engineering and Technology (IJMET) Volume 7, Issue 3, May-June 2016, pp.213-224, Article ID: IJMET_07_03_020 Available at: http://www.iaeme.com/IJMET/issues.asp?JType=IJMET\&VType=7\&IType=3

7. Guiqiang Wang, Pinghua ZouMathematical Modeling of Food Freezing in AirBlast Freezer, International Journal of Materials, Mechanics and Manufacturing, Vol. 2, No. 4, November 2014, pp. 278-282, http://www.ijmmm.org/papers/142-TT3008.pdf

8. Maria Justo Alonsoa *, Trond Andresena, Frode Frydenlunda, Kristina N. Widellb, Improvements of air flow distribution in a freezing tunnel using Airpak, 11th International Congress on Engineering and Food (ICEF11), Procedia Food Science, 1, (2011), 1231-1238, https://core.ac.uk/download/pdf/82600162.pdf 
Resource and Energy Saving Technologies of Production and Packing of Food Products as the Main Fundamentals of Their Competitiveness: Proceedings of the 7th International Specialized Scientific and Practical Conference, September 13, 2018. Kyiv, Ukraine

9. Chanya Uraijaree, Kiatfa Tangchaichit Jarupol SuriyawanakulComparison of airflow-uniformity in different ceiling-diffuser designs with various concentric circles in shrimp freezer using CFD, IOP Conf. Series: Earth and Environmental Science 113 (2018) 012205, http://iopscience.iop.org/article/10.1088/17551315/113/1/012205/pdf

10.Christoph Josef BackiModeling, Estimation and Control of Freezing and Thawing Processes, Thesis for the degree of philosophiae doctor Trondheim, December 2015, 219 p.

Available at: http://folk.ntnu.no/tomgra/Backi_thesis.pdf

11.O. Rouaud, Q.T. PhamHeat and Mass Transfer Modelling During Freezing of Foodstuffs, Proceedings of the 2012 CONSOL Conference Milan. https://www.comsol.jp/paper/download/151871/rouaud_paper.pdf

12.Hector A. Jimenez-Avalos*, Leandro Chaires-Martinez and Miguel A. PerezVargas. Prediction of Freezing Time and Evaluation of the Effect of Frozen Storage on Textural Properties of White Trout Fillets, Food Sci.Technol. Res., 19(3), 375-379, 2013. https://www.researchgate.net/publication/276200863_ 